\title{
Kernos
}

Revue internationale et pluridisciplinaire de religion grecque antique

$25 \mid 2012$

Varia

\section{Pierre CARLIER, Charlotte LEROUGE-COHEN (éds), Paysage et religion en Grèce ancienne. Mélanges offerts à Madeleine Jost}

\section{Corinne Bonnet}

\section{OpenEdition}

\section{Journals}

Édition électronique

URL : http://journals.openedition.org/kernos/2089

DOI : 10.4000/kernos.2089

ISSN : 2034-7871

\section{Éditeur}

Centre international d'étude de la religion grecque antique

\section{Édition imprimée}

Date de publication : 26 octobre 2012

Pagination : 381-382

ISSN : 0776-3824

Référence électronique

Corinne Bonnet, «Pierre carlier, Charlotte lerouge-cohen (éds), Paysage et religion en Grèce ancienne. Mélanges offerts à Madeleine Jost », Kernos [En ligne], 25 | 2012, mis en ligne le 01 octobre 2012, consulté le 21 septembre 2020. URL : http://journals.openedition.org/kernos/2089 ; DOI : https:// doi.org/10.4000/kernos.2089

Ce document a été généré automatiquement le 21 septembre 2020 


\title{
Pierre CARLIER, Charlotte LEROUGE- COHEN (éds), Paysage et religion en Grèce ancienne. Mélanges offerts à Madeleine Jost
}

\author{
Corinne Bonnet
}

\section{RÉFÉRENCE}

Pierre CARLIER,Charlotte LEROUGE-COHEN, Paysage et religion en Grèce antique. Mélanges offerts à Madeleine Jost, Paris, De Boccard, 2010. 1 vol. $16 \times 23,5 \mathrm{~cm}, 272$ p. (Travaux de la Maison René-Ginouvès, 10). ISBN : 978-2-7018-0285-5.

1 Ce beau volume d'hommage à Madeleine Jost s'ouvre sur une évocation touchante, par Jean Marcadé, de cette arrière-petite-fille de Charles Guignebert, qu'une forme d'héritage orienta tout naturellement vers l'Antiquité et ses religions. Dans le paysage des souvenirs, on voit très tôt apparaître l'Arcadie et Pausanias, regroupés au sein d'une thèse, présentée en 1972. «Elle reprenait en $4 \mathrm{~L}$ et surtout à pied des chemins qui n'avaient guère changé depuis Pausanias et scrutait le relief tourmenté de l'Arcadie antique. » C'est donc très naturellement sur ces deux « amours » de Madeleine Jost que se concentrent deux des trois sections regroupant les contributions, la troisième section étant consacrée à "la religion grecque " en général. Conçu comme une "invitation au voyage», selon les mots du regretté Pierre Carlier et de Charlotte Lerouge-Cohen, le volume contient 24 contributions de qualité, accompagnées d'une bibliographie de M. Jost (aux p. 267-272). On pourra d'emblée regretter que le titre ne soit rien d'autre qu'un énoncé général susceptible d'accueillir les apports des littéraires, des historiens, des archéologues, des épigraphistes, des historiens de l'art ou des religions, alors qu'il propose un binôme fort intéressant que l'on aurait aimé voir problématisé dans l'Introduction. Pour mieux saisir les enjeux de l'inscription des 
cultes dans des paysages naturels ou non, on pourra lire le $4^{\mathrm{e}}$ fascicule (2010) de la Revue de l'Histoire des religions, ouvert par une contribution de Fr. de Polignac et J. Scheid, intitulée "Qu'est-ce qu'un 'paysage religieux'? Représentations cultuelles de l'espace dans les sociétés anciennes »,p. 427-434, mais aussi A. Dierkens \& A. Morelli (éds), Topographie du sacré. L'emprise religieuse sur l'espace, Bruxelles, 2008 ; E. Olshausen \& V. Sauer (éds), Die Landschaft und die Religion, Stuttgart, 2009 et M.C. Cardete del Olmo, Paisaje, identitad y religion,Barcelone, 2010 (en Sicile essentiellement).

2 La $1^{\text {re }}$ section du volume concerne l'Arcadie, avec ou sans Pausanias : l'Arcadie et son "paysage » dynastique (P. Carlier), l'Arcadie et ses paysages «noirs» (M. Casevitz), l'Arcadie et ses particularités dialectales (L. Dubois), les fouilles du sanctuaire d'Artémis Héméra à Lousoi en Arcadie (V. Mistopoulos-Leon), l'identification de trois agglomérations arcadiennes mentionnées par Pausanias (Y.Pikoulas), la création du Parc du Patrimoine parrhasien dans la région du Lykaion (D. Gilman-Romano \& M.E. Voyatzis), le sanctuaire de Pan et Hermès à Bérékla à la frontière entre Arcadie et Messénie (J. Roy).

$3 \quad$ La $2^{\mathrm{e}}$ section regroupe des contributions sur la religion grecque en général; il y est question des dieux nikèphoroi de Taposiris Magna, à l'ouest d'Alexandrie (M.Fr. Boussac), du mythe de Pélops, le gendre, et d'Hippodamie, la fille épiclère, avec ses prolongements éponymiques et toponymiques dans un Péloponnèse audacieusement qualifié de «sympolitique»(P.Brulé), de plaques en terre-cuite archaïques et classiques du Musée de Sparte désignées comme "reliefs héroïques» et ici mis en rapport avec le domaine de Zeus Lakedaimonios (J.Christien), sur l'Achéen Oibotas, combattant à Platées et olympionice devenu héros plusieurs siècles après sa mort (V. Cuche), des termes enthymios et enthymistos en rapport avec une faute potentielle et la menace d'être frappé par la colère divine (K. Karila-Cohen), de Kalynthos/Kalyndos, dieu-fleuve thébain, frère d'Hisménos, qui formaient ensemble des fleuves jumeaux en rapport avec la topographie de la Cadmée mais aussi avec le destin de Thèbes déchirée par les rivalités familiales (D. Knoepfler), de la consommation de viande par les Grecs, lors des sacrifices et en dehors de ceux-ci (R. Parker), de l'attribution à Athéna Polias ou à Erechthée de l'oikèma de l'Acropole mentionné par Pausanias (V. Pirenne-Delforge), d'Alcméon et Amphilochos, les deux fils d'Amphiaraos, liés initialement au thème du matricide, devenus des figures de l'errance en quête de nouveaux horizons susceptibles de les inscrire dans de nouveaux cadres historiques (Fr. de Polignac), des apports respectifs de l'archéologie, des sciences de la nature et des textes à la connaissance du fonctionnement de l'oracle de Delphes (G. Rougemont), de la vertu et de l'hérö̈sme féminins confrontés à un horizon politique masculin qui en fixe les limites et détermine les valeurs que l'aretè féminine doit défendre (P. Schmitt Pantel), du sanctuaire aux niches indentées d'Aï Khanoum dédié à Zeus et de ses deux temples successifs (L. Martinez-Sève).

4 Une ultime section rassemble quelques études sur Pausanias, à commencer par celle qui porte sur les digressions dans lesquelles le Périégète évoque l'Occident, eschatia digne de l'âge d'or, où pourtant Grecs et Barbares s'affrontent non sans cruauté (A. Jacquemin). Il est encore question de références au monde barbare et de la complexité de la représentation du monde que véhicule Pausanias (C. Lerouge-Cohen). Trois contributions clôturent le volume: sur l'Épaminondas de Pausanias (homme admirable, sans ombre) comparé à celui de Xénophon (caractérisé par des falsifications) (M. Moggi), sur le recours à l'ekphrasis dans le De Signis de Cicéron pour fustiger Verrès 
le pilleur d'œuvres d'art qui détruit la mémoire culturelle de la Sicile, une démarche qui mérite une comparaison avec celle de Pausanias (A. Rouveret) et enfin, comme pour boucler la boucle avec la section initiale, une étude sur les mythes arcadiens dans le livre VIII de Pausanias, ses sources, la place qu'il leur donne, les choix qu'il opère et le label de « sagesse » qu'il leur attribue (S. Saïd).

5 Au final, un ouvrage riche et varié qui rend dignement hommage à une collègue unanimement estimée.

\section{AUTEURS}

\section{CORINNE BONNET}

Université de Toulouse - Le Mirail / IUF 